\title{
ECONOMIC ANALYSIS OF THE PRINCIPLES OF LIABILITY IN TORT IN THE BACKDROP OF LIABILITY FOR COMPENSATION FOR DAMAGE OCCURRING AS A RESULT OF THE ACTIVITIES OF ONE ENTITY TO THE GOODS OF ANOTHER ENTITY
}

\author{
JOANNA KUŹMICKA-SULIKOWSKA*
}

\section{INTRODUCTION}

The use of economic sciences tool for performing analyses of legal regulations constitutes one manifestation of the increasingly frequent application of interdisciplinary research, whose primary goal is to achieve a new perspective on problems present within the scope of defined scientific fields, a multi-aspect approach to the examined phenomena and the creation of an increasingly cohesive knowledge system. The application of economic methods to law is nothing new. It is sufficient to point out that this has taken place within the framework of Roman Law, Marxist Theory of Law, American Legal Realism, Hermeneutics and methods for legal reasoning. ${ }^{1}$ However, the beginnings of scientific trends of economic analysis of law in the strict sense (Law and Economics) date back to the 1960s, in the scientific work performed by members of the so-called 'Chicago school'.2 Looking at law through the prism of economics quickly became a popular field of research, which included within its scope civil, criminal, constitutional and insurance law.

DOI: 10.2478/wrlae-2013-0010

* PhD in Law; Assistant Professor, Department of Civil Law and International Private Law at the Faculty of Law, Administration and Economics, Wroclaw University; j.kuzmicka@prawo.uni.wroc.pl.

${ }^{1}$ More details can be found in J Stelmach, 'Spór o ekonomiczną analizę prawa' in J Stelmach and M Soniewicka (eds), Analiza ekonomiczna $w$ zastosowaniach prawniczych (Wolters Kluwer 2007) 9-11.

${ }^{2}$ As breakthrough works for initiating this type of approach to law the following should be mentioned: G Calabresi, 'Some Thoughts on Risk Distribution and the Law of Torts' (1961) 70 YLJ 497; G Calabresi, The Cost of Accidents: A Legal and Economic Analysis (Yale University Press, New Haven 1970); R Coase, 'The Problem of Social Cost' (1960) 3 JLE 1; A Alchian, 'Some Economics of Property Rights' (1965) 30 Il Politico 816; GS Becker, 'Crime and Punishment: An Economic Approach' (1968) 76 JPE 169; RA Posner, Economic Analysis of Law (Little, Brown and Company, Boston 1972). 
The present article discusses a narrow fragment of these issues, and in particular certain aspects connected to economic analysis of the principles of liability in tort in the backdrop of liability for compensation for damage occurring as a result of the activities of one entity to the goods of another entity. Due to the limited framework of the present work, the discussion on the subject will not be exhaustive, but rather limited in scope to selected aspects. Within the remaining areas the reader will be referred to literature on the subject. ${ }^{3}$ Within the scope of the preliminary issues it should also be pointed out that the concept of liability principles used in the title of the article will not be understood colloquially, i.e. in a broad sense, as encompassing the principles governing this liability, but in a rather narrow sense, as pertaining to such principles of the said liability as fault or risk. ${ }^{4}$ Furthermore, as one would expect, due to the profile of the work, comments included within the article will focus on legal aspects and deductions of economic analysis as presented in the subject literature, and as such will constitute the basis for the conclusion. Therefore, as regards detailed mathematical issues the reader is referred to the extensive literature on the subject. $^{5}$

\section{AN ANALYSIS OF A CLASSIC EXAMPLE OF CAUSING DAMAGE TO ANOTHER ENTITY AS A RESULT OF ONE'S OWN ACTIONS BASED ON EXAMPLES OF VEHICLE ACCIDENTS}

Conducting detailed considerations requires an introductory explanation to the effect that subsequent comments will substantially relate to model situations, frequently referred to in literature on the subject by the name of unilateral and bilateral accidents. ${ }^{6}$ In respect of the former, it is usually assumed that the danger of damage-causing events occurring is dependent solely upon the degree of carefulness on the part of the potential perpetrators within the scope of their actions (employed precautions), whereas the potentially aggrieved individuals have no influence over this situation, or the role of this factor is so insignificant that it can be

\footnotetext{
${ }^{3}$ Eg with reference to car accidents see in particular: S Shavell, An Economic Analysis of Accident Law (Harvard University Press 1987); S Shavell, Ekonomiczna analiza prawa wypadków (Transformacje Prawa Prywatnego. Numer Amerykański, Wydawnictwo Uniwersytetu Jagiellońskiego 2005,); S Shavell, 'Liability for accidents' in AM Polinsky and S Shavell (eds), Handbook of Law and Economics, vol. I, (Elsevier 2007); AM Polinsky, An Introduction to Law and Economics (2nd ed, Little, Brown and Company, Boston and Toronto 1983) 39-52; EM Landes, 'Insurance, Liability and Accidents: A Theoretical and Empirical Investigation of the Effect of No-Fault Accidents' (1982) 25 JLE 49-65; FA Sloan, BA Reilly and CM Schenzler, 'Tort Liability versus Other Approaches for Deterring Careless Driving' (1994) 1 IRLE 140-144.

${ }^{4}$ For more details on this approach see J Kuźmicka-Sulikowska, Zasady odpowiedzialności deliktowej w świetle nowych tendencji w ustawodawstwie polskim (Wolters Kluwer 2011) 23-40.

${ }^{5}$ See eg: R Cooter and T Ulen, Ekonomiczna analiza prawa (J Bełdowski, J Czabański, K Metelska-Szaniawska, M Olender, and B Targański trs, CH Beck 2009) 395-500.

${ }^{6} \mathrm{Eg}$ in Shavell (n 3) 14-43.
} 
overlooked without affecting the outcome. ${ }^{7}$ On the other hand, bilateral accidents are those situations in which both the behaviour of the perpetrators as well as the aggrieved influence the probability of occurrence of a damage-causing event. Thus in the latter case, the actions of both categories of entities and the carefulness applied by them influence the risk of the occurrence of damage, for example as a result of an accident. ${ }^{8}$ Essentially, talking about unilateral or bilateral accidents constitutes a certain terminological simplification, as in actual fact this pertains to whether the possibility of employing precautions preventing the occurrence of an accident rests only on one of the parties or on both 'parties to the accident' (that is, both its perpetrator and the aggrieved). That is why sometimes the concepts of unilateral and bilateral carefulness are used respectively, ${ }^{9}$ which reflects the model assumptions. Keeping this in mind, in the following sections of my reasoning I will alternatively apply those concepts, as well as those of 'unilateral accident' and 'bilateral accident', in order to achieve conciseness and to avoid repetitions.

Moving on to more detailed considerations, it should be emphasised that both in the case of unilateral accidents and bilateral accidents, the goal set for the principles of tortious liability is the same; namely, to strive for minimisation of the total social costs associated with these events. ${ }^{10}$ It is true that a gradual increase in the level of carefulness leads to an appropriate reduction of the risk of occurrence of damage, and following on from this, only at the highest possible level of carefulness does the maximum reduction of this risk take place. However, the optimal situation is such a formulation of legal regulations and the adoption of such principles of tortious liability under which the costs of taking precautions will be profitable in the context of avoidance of accident risk, and thus the

\footnotetext{
${ }^{7}$ However, sometimes it is assumed that within the framework of this model one of the parties, the perpetrator or aggrieved, may employ safety means preventing the occurrence of loss (for more on this issue see comments in section IA).

${ }^{8}$ In the literature sometimes even three models are assumed: unilateral, bilateral and multilateral, indicating that the basis for differentiating between them constitutes how the optimal level of carefulness is determined within their framework. In a unilateral model, such a level is achieved when the tort perpetrator may reduce the expected level of losses by one unit in return for each unit of increased carefulness. In a bilateral model, one may speak of an optimal level of carefulness when each of the parties, thus both the tort perpetrator and the aggrieved, may reduce the expected losses by one unit through each one unit increment in the carefulness employed in their behaviour. In a multilateral model, it is assumed that the optimal level of carefulness occurs when each tort perpetrator and each aggrieved can lower the expected losses by a one-unit increase in the measure of their meticulousness (HB Schäfer and C Ott, The Economic Analysis of Civil Law (M Braham tr, Edward Elgar Publishing 2004) 115.

${ }^{9}$ Cooter and Ulen (n 5) 412.

${ }^{10}$ In this context, it should be pointed out that in the literature on the subject the following argument is raised: 'Economic goal of liability in tort constitutes in persuading the perpetrator and aggrieved to internalize the costs of losses, which may ensue from not employing precautions. Tort law internalizes these costs, forcing the perpetrator to compensate the aggrieved. When individuals, who may potentially cause loss, internalize these costs, that gives them incentives to invest in safety at an effective level. The economic concept of tort law constitutes in applying the principle of liability to internalise the external effects occurring due to high transaction costs.' (Cooter and Ulen (n 5) 393).
} 
level of carefulness desirable from the point of view of social welfare does not necessarily have to be - and in fact usually is not - the highest achievable in practice.

In real life, accidents which fit into the unilateral model framework occur less frequently than those in the bilateral model, as it is rare that a given event classified as tort ${ }^{11}$ is dependent upon the actions of only one of the parties (e.g. the perpetrator), and the aggrieved is not able to employ any precautions in order to reduce the risk of suffering damage. More often, the other party can also employ certain precautions. ${ }^{12}$ For this reason, the discussion on unilateral accidents will be briefer than that on bilateral ones. Nevertheless it is essential to examine them, especially as, given a certain measure of simplification indicated in the relevant subject literature, the principles governing them can also be successfully applied in situations where the role of the aggrieved is slight and of minimum significance to the course of events. A significantly greater number of everyday events resulting in the occurrence of damage to a person or property fit the bilateral model, and as such it will be discussed in greater detail.

\section{A. The unilateral model}

In the case of the unilateral model, when the legislator assumes a lack of liability on the part of the perpetrator for the damage he causes, for obvious reasons the latter will not be careful within the scope of his actions. As he will not have to compensate the aggrieved in the event of an occurrence of damage, he will not pay any attention to reducing the probability of its occurrence. The entirety of the damage will remain exactly where it arose, that is to say there will be no allocation of costs associated with the said damage, the burden of which would rest on the aggrieved entity. Alternatively, if the perpetrator's liability is established and based on the risk principle, he is motivated to choose a socially optimal level of carefulness as only in this way will he be able to reduce the costs he incurs. In adopting the risk principle he is obliged to compensate for all damage he has caused (assuming the conditions for liability are met, of course, but

\footnotetext{
${ }^{11}$ Nota bene, within the framework of individual countries' legal systems one may observe certain discrepancies between the scope of events qualified by regulations as torts (for more information see Ch von Bar, The Common European Law of Torts, vol. 1, The Core Areas of Tort Law, its Approximation in Europe, and its Accomodation in the Legal System (Clarendon Press 1998) 2-11; J Kuźmicka-Sulikowska, Odpowiedzialność deliktowa w prawie wybranych państw obcych (Prawnicza i Ekonomiczna Biblioteka Cyfrowa 2011) 912.

${ }^{12} \mathrm{Eg}$ as a situation where only the potential loss perpetrator may employ safety means and the potentially aggrieved is devoid of such possibility, and thus as an example of the unilateral carefulness model, a situation where a surgeon is operating on an unconscious patient is given (Cooter and Ulen (n 5) 408). However, once the circumstances are altered, if the surgeon spoke to the patient beforehand about the illness and the necessity of invasive surgery, the situation may be different. As even if the surgery was conducted after pharmacological sedation of the patient and its course was in essence dependent upon the skills of the surgeon, then in such a case, if the patient had not provided significant information regarding illnesses from which he is suffering, medicines which he is taking or is allergic to during the earlier conversation with the doctor this may influence the course and success of the surgery. What follows is that the patient and potentially aggrieved party may have an opportunity to undertake certain precautions reducing the probability of the occurrence of loss. In such an event, it would be more appropriate to talk about a model of bilateral carefulness.
} 
regardless of whether he was at fault or not). On the other hand, establishing perpetrator liability for damage subject to the existence of fault on his part results in his being released from the burden of compensation only if he maintains at least the minimum level of carefulness, which is established by the courts in the course of applying the law. If the courts define the level of carefulness at a socially optimal level then the perpetrator of the damage will be inclined to observe it. ${ }^{13}$ In such a case, potential perpetrators of damage will not undertake to observe higher standards of carefulness, as they will be rendered unprofitable when taking into account that there will be no risk of liability when a lower standard is met. However, neither will they undertake to maintain a level of carefulness below that which is sufficient, as then they would have to pay compensation for each case of damage caused. ${ }^{14}$

Thus the conclusion may be drawn that, within the framework of a unilateral accident model, both basing liability in tort on the principle of risk as well as of fault lead to socially optimal outcomes by motivating potential perpetrators to maintain an appropriate level of carefulness. During the evidentiary phase of civil proceedings the application of the second principle leads to practical problems, requiring not only proof of the fact by which the damage was caused, the occurrence and scope of the damage and the causal relationship between these elements, but also the establishment by the court of a socially optimal level of appropriate carefulness and demonstration by the aggrieved that the perpetrator did not observe this level (this last element, however, is dependent upon the solutions adopted within the given legal system and will be different if the legislator has introduced a presumption of fault). Thus taking into account the additional factor of administrative costs during deliberations results in the indicated balance between the principles of liability in tort being distorted for the benefit of the principle of risk, in which case a smaller number of circumstances require proving during court proceedings than in the case of liability dependent upon fault on the part of the perpetrator. ${ }^{15}$

\footnotetext{
${ }^{13}$ SM Shavell, Law and Economics in HE Jackson, L Kaplow, SM Shavell, W Kip Viscusi and D Cope, Analytical Methods for Lawyers (Foundation Press 2003) 398. These authors emphasise that it is sufficient to apply perpetrator liability based on a simple principle of fault in the form of negligence (the negligence rule), without the need to amend it by affording the defendant a possibility to plead that the aggrieved claimant acted negligently (the defense of contributory negligence), as the fault principle itself as justification for a tortfeasor's liability is a sufficient stimulant to incline potential accident victims to employ appropriate meticulousness. This stems from the fact that as loss perpetrators, in order to avoid liability, will maintain appropriate meticulousness, then the aggrieved, being conscious of the fact that the perpetrators will act in such manner and that the entire weight of the loss occurred will rest on the shoulders of the aggrieved, will also be inclined to maintain appropriate safety so that the probability of occurrence or scope of loss is reduced (Shavell, (n 13) 401.

14 Shavell (n 3) 17; AM Polinsky, Introduction to Law and Economics (3rd ed, Aspen Publishers 2003) 46.

15 TJ Miceli, Economics of the Law. Torts, contracts, property, litigation (Oxford University Press 1997) 17. However, it should be noted that it is pointed out in the literature that adopting liability in tort based on the principle of fault results in a smaller number of claims pursued, as they are more difficult from a process point of view (the number of
} 
The above viewpoint is dominant, but is not the only one represented in the literature. A slightly different standpoint can also be found which is applied to events that fit the unilateral model not in the manner in which it is presented above (i.e. situations where only the conduct of the perpetrator of the tort influences the level of danger of occurrence of damage, and the behaviour of the aggrieved does not play any role within this scope), but is applied to cases where only one entity has control over the factors which result in the occurrence of damage, the difference being that such entity can be either the tort perpetrator or the aggrieved. With such an understanding of unilateral accidents, in the event that the legislator does not establish any burden of liability on the perpetrator for damage caused by him, there will be no incentive for this perpetrator to conduct himself carefully and it is the potentially aggrieved who will take precautions, being mindful that the weight of the possible damage caused by the tort perpetrator will be borne by him.

Thus, here the aggrieved entity is burdened with both the costs associated with the damage as well as the requirement to employ precautions in order to reduce the risk of suffering this damage. Both of these burdens will be borne by him as long as it remains economically effective to do so, that is as long as increasing expenditures for precautions will result in a reduction of the expected costs associated with the damage. Here the aggrieved will be motivated to achieve an economically optimal level by reaching the marginal value of costs and benefits flowing from the employed precautions. In the event of a legal solution under which tort liability is based on the risk principle, assuming perfect compensation (meaning it is equal to damage) for damage suffered by the aggrieved, there is no incentive for him to undertake preventative action. ${ }^{16}$ This is because incurring costs associated with such means would not yield any benefits in the form of a reduction in the probability of an accident. In this case different incentives influence the potential tort perpetrator, who, on the grounds of liability based on the risk principle under the assumption of complete compensation, is obligated to pay in full for all damage he causes. Therefore, he is motivated to maintain an economically effective level of caution in his conduct in order to attain the marginal value of costs of carefulness and the benefits flowing thereof. These deliberations lead to the conclusion that the adoption of a lack of liability on the part of tortfeasors for damage caused by them should be preferred within those areas in which only potential victims have the ability to undertake means to prevent accidents or decrease the risk thereof, whereas the adoption of the risk principle as justifying tortfeasor's liability is advisable when only he may undertake means to prevent accidents. ${ }^{17}$

circumstances requiring demonstration), whereas the application of liability in tort based on the principle of risk implicates bringing more compensation claims, which are easier to adjudicate (Cooter and Ulen (n 5) 438.

${ }^{16}$ It seems that this may pertain at most to losses to chattels, but not to non-material losses to a person. Furthermore, the assumption of full, perpetually available loss compensation seems unrealistic. This will be discussed in more detail in the article.

${ }^{17}$ R Cooter and T Ulen, Law and Economics (4th ed, Pearson Addison Wesley 2003) 323 325 . 


\section{B. The bilateral model}

In respect of bilateral accidents it should be borne in mind that, due to the aforementioned significance of the behaviour of both parties to the probability of occurrence of damage, the behaviour of the damage perpetrator is often related to the conduct of the other party.

In such cases, if the legislator does not establish the perpetrator's liability, similarly to the unilateral model a potential perpetrator has no motivation to exercise carefulness in his activities. This burden will fall on the potentially aggrieved, which stems from the fact that they will incur the entire burden of the damage, by which they will be effectively motivated to undertake precautions. The situation is reversed if the legislator establishes perpetrator liability based on the risk principle, as then the obligation to pay compensation will rest on the perpetrator, by which he will be inclined to maintain carefulness as opposed to the aggrieved whose damage will be compensated by the perpetrator in every case. ${ }^{18}$ Thus, it is difficult to judge both such situations as satisfactory and socially optimal. Other principles of liability in tort are more favourable to the achievement of such a result, for example perpetrator liability based on the principle of risk but modified by the possibility of raising a charge of contribution of the aggrieved. In such a case the maintenance of an appropriate level of carefulness by the aggrieved results in a shift of the entire burden of compensation for damage onto its perpetrator, whereas insufficient carefulness on the part of the aggrieved leads to the conclusion that he contributed to the occurrence of damage and therefore should also bear some of the burden of damage. Thus, the aggrieved will be motivated to maintain an appropriate level of carefulness, and tortfeasors, being able to assume such conduct on the part of potential victims, will also act in a careful manner in order to avoid the need to pay compensation. This mechanism works equally well on the principle of a mirror image in relation to the aggrieved, that is, assuming careful conduct by a potential perpetrator unwilling to bear the costs of damage compensation, the aggrieved will also behave with appropriate carefulness.

The distribution of factors affecting the behaviour of people in the event of defining fault as the principle for liability is slightly different. Here, under the assumption that the level of carefulness required by the courts is optimal, the perpetrators will strive to observe it due to the profitability of this method in the context of minimising the risk of causing damage and bearing the costs associated with compensation. At the same time, the possibility of forecasting the observance of carefulness by the perpetrators that would prevent them from facing charges of fault and the ensuing burden of an obligation to pay compensation simultaneously acts as a stimulus for the aggrieved who, in the event of a lack of carefulness within the scope of his own activity, will bear the burden of damage alone.

However, if the situation is slightly different, that is when fault is the binding principle of liability, but with the possibility of raising a charge of contribution by the aggrieved, the obligation to compensate damage lies on the perpetrator only if in a given situational set he is the only party failing to

\footnotetext{
${ }^{18}$ However, see comment in footnote 16.
} 
observe the minimum necessary carefulness, assuming the aggrieved has maintained the required degree of carefulness. The lack of an appropriate level of carefulness on the part of the latter (or a higher level, which would no longer be a socially optimal one) leads to an outcome under which the economic burden of the damage will be located within his assets and the perpetrator will be free from such. Again, the role of the courts seems of particular significance here, because if they define the level of appropriate carefulness at a socially optimal level then both perpetrators and the aggrieved will strive to observe it, having a real and solid basis to assume that the opposing party will act rationally so as to avoid the necessity of bearing the material consequences associated with compensation for damage and will also observe this socially optimal level of carefulness. ${ }^{19}$ Nevertheless, it is indicated in the literature that the introduction of the fault principle with a modification allowing the possibility to take into account an additional element in the form of the contribution of the aggrieved to the occurrence of damage is not required, as the goal of inducing the aggrieved to observe careful conduct in his activities (which is a socially desirable and optimum effect) is achieved by mechanisms governing the behaviour of the parties on the grounds of 'pure' fault principle. ${ }^{20}$ Certainly in both cases a very powerful motivation is present for the perpetrators to behave carefully, however this element does not raise any doubts in the light of model assumptions adopted at the time of establishing tortious liability of the perpetrator based on the principle of fault or the principle of fault with the charge of aggrieved contribution, whereby the perpetrator is assumed to be the primary entity to which compensatory liability is assigned. Similarly, the element of motivating the perpetrator to act with an appropriate level of carefulness will be present when the legislator applies a method based on a comparison of fault. Here as well the perpetrator will escape the requirement to pay compensation if he has exhibited appropriate carefulness in his actions. A significant difference within the scope of incentives stemming from the form of legal regulations shaping the actions of entities in a given situation occurs within the boundaries of the principle of fault comparison when the standard for conduct reflecting the level of appropriate carefulness is met by neither the perpetrator nor the aggrieved. In such a situation, given the aforementioned liability principle, both parties (that is, both the perpetrator and the aggrieved) have to compensate for the damage resulting from an accident or other damage-causing incident, whereas the participation of each party in this cost is dependent upon the degree to which their conduct diverged from the established socially optimal level of appropriately careful behaviour. And thus, under an appropriate - that is, economically effective - establishment of a model of required appropriate carefulness, both the perpetrator and aggrieved will be inclined to observe it. Thus, despite different constructions of the legal incentives affecting the motivation of the parties for choosing their method of conduct, the final result as to the preferences of the parties is the same as in the case of perpetrator liability based on the principle of fault or on the principle of

\footnotetext{
${ }^{19}$ P Diamond, 'Accident Law and Resource Allocation' (1974) 10 BJE 366-405; Schäfer and Ott (n 8) 189.

${ }^{20}$ Shavell (n 3) 23.
} 
fault with the possibility to raise charges of contribution by the aggrieved to the occurrence of damage.

In light of the above comments, it should be considered that basing liability on the principle of risk with the possibility of bringing up charges of contribution by the aggrieved as well as on the principle of fault, the principle of fault with the option to take into account the contribution of the aggrieved and the principle of comparison of fault leads to socially optimal results. $^{21}$ In all of these combinations, with the aid of multidirectional motivational factors, a situation is achieved in which the parties are effectively motivated to pay attention so that, within the scope of their activities, the appropriate level of carefulness is observed. Such a result is not achieved by establishing regulations which do not take into account perpetrator liability for damage suffered as a result of his acts or omissions or by founding his liability on a simple principle of risk.

Despite the fact that as many as four of the aforementioned combinations of liability principles lead to results desired by a rationally acting legislator, their structures differ significantly, and the boundary between the principle of fault in all its versions and the principle of risk is clear. This is manifested not only in the aforementioned various distributions of incentives with the aim of inclining the parties to maintain the desired carefulness in activities. Differences also occur within the procedural sphere, by the establishment of the necessary scope of evidence and the ensuing scope of administrative costs associated with the functioning of particular liability principles in practice. This stems from the general ascertainment that, to obtain a court verdict awarding the claimed compensation on the grounds of the fault principle, it is required not only to demonstrate the occurrence of the fact constituting the source of the damage, the damage itself and the cause-and-effect relationship between them (just as under the risk principle), but furthermore it is necessary for the court to establish such a level of appropriate carefulness which is, in given circumstances, socially optimal and economically effective, as well as a demonstration by the aggrieved that the perpetrator did not observe such carefulness in his own actions.

It transpires that not only is the legislator's choice of principle for a given category of situations of significance, but equally important in the determination of the effects of principles of liability on the behaviour of potential damage perpetrators and aggrieved is how they function in everyday life, and thus what factors, be they from the perspective of case law, economic mechanisms or psychological factors, become relevant for the functioning of particular liability principles and additionally shape the behaviour of people under a given legal regime. Among the most important factors are the methods which will be employed by the courts for

${ }^{21}$ Polinsky (n 14) 50. It should be remembered that these options of 'combinations of principles' are formulated by authors functioning within foreign legal systems and thus will not always find a direct reflection in the Polish law, as within its framework e.g. the occurrence of loss solely by the fault of the aggrieved often constitutes exonerating circumstances from liability, that is excluding it (see eg art 433, art 435 and art $436 \S 1$ of the Polish Civil Code). 
determining the level of required appropriate carefulness and their capacity to do so at a socially optimal level, as well as the fact that the parties' inclination to undertake behaviour which could result in the occurrence of damage is not only affected by the principle governing their liability but also the scale of their activity, how often they undertake it, what their profits from it are and what the probability of causing damage is. No less significant are factors of a very subjective character, such as a general willingness to assume risk.

\section{The level of appropriate carefulness}

The correct functioning of the incentives envisaged by the legislator which are to affect the behaviour of the parties in situations where liability is based on the fault principle, is dependent to a large extent on how courts in practice establish the level of appropriate carefulness. Only a proper definition thereof leads to the attainment of socially beneficial results, which will minimise social cost to the largest possible extent.

In general it is indicated that, in the process of reasoning which is to achieve the establishment of a model for the proper level of carefulness required in a given situation, first and foremost the costs associated with the undertaking of individual behaviour reducing the risk of causing damage or eliminating them entirely should be taken into account, as well as the danger of causing damage as a (usually secondary) consequence of one's acts or omissions. In balancing the relation between these elements some authors propose that rules of equity should be followed ${ }^{22}$, whereas others prefer calling upon more measurable and material factors such as the probability of damage occurring, its potential scope, whether only assets are in danger or also a person's well-being, how large the group subject to the potential effects of the danger is, and whether the perpetrator could reduce the danger he generated with relative ease or rather only by incurring significant expense. $^{23}$

Generally speaking, if the precautions undertaken by the damage perpetrator are less than appropriate, then the marginal social cost associated with undertaking these means is less than the associated value of marginal social benefit, whereas if the perpetrator undertakes precautions greater than those indicated by effectiveness reasons, the marginal social costs associated with observing this carefulness exceeds the ensuing social benefits. This supports the conclusion that it is economically effective in such cases for the perpetrator to apply reduced preventative means. ${ }^{24}$ In the former situation, to achieve an economically effective outcome the perpetrator should observe a higher level of carefulness than that which was actually applied by him, so from the perspective of an economic analysis of his behaviour it is justified to charge him with not observing the appropriate level of carefulness in his activities. On the other hand, in the latter situation, the damage perpetrator has observed an even higher level of carefulness than that indicated by principles of economic effectiveness, and there is no way to charge him with not observing appropriate carefulness. In

\footnotetext{
${ }^{22}$ Shavell (n 3) 27.

${ }^{23}$ W Prosser, WP Keeton, DB Dobbs, RE Keeton, DG Owen, Prosser and Keeton on the Law of Torts (5th ed, West Publ. 1984) chapters 29-33.

${ }^{24}$ Cooter and Ulen (n 17) 322.
} 
such an event, he will be free from liability based on the principle of fault in the form of negligence.

The most precise concept regarding the establishment of the appropriate level of carefulness, applying mathematical tools, was proposed by Judge Learned Hand on the basis of one of his cases. ${ }^{25}$ Due to its clarity and operability, this method has gained broad acceptance in case law. ${ }^{26}$ Hand took into account three main elements, that is the cost of undertaking preventative means which he designated $B$ (burden of the cost of the precaution), the probability of the occurrence of loss if no preventative means are employed (designated $P$ for probability) and the scope of the loss (designated $L$ for loss). He then indicated that one may speak of the perpetrator not observing the appropriate carefulness, and thus of his fault, only if $\mathrm{B}<\mathrm{PL}$, that is when the costs associated with the undertaking of precautions by the perpetrator were smaller in a given case than the probability of damage occurring under the conditions of no preventative measures being undertaken by the perpetrator multiplied by the damage value. Only in such a situation would it be sensible and economically optimal to require the potential perpetrator to undertake measures to protect his surroundings from suffering damage. ${ }^{27}$

However, in practice Hand's formula appears to be an imperfect solution. ${ }^{28}$ Firstly, it is has been observed that it requires improvement by defining the scope of its application, as it does not exceed the limits established by measuring and comparing the marginal expected costs of an accident (in terms of damage which requires compensation) with the costs of preventative measures. Here it is recommended to carry out an assessment of the expenditures and profits associated with incremental increases in safety (in other words, with a gradual decrease in the risk of causing damage), and to acknowledge that it is rational and optimal that the potential perpetrator should stop employing further damage prevention precautions at the moment when each additional dollar spent for this purpose would generate additional safety of a value equal or less to that dollar. Such a metric indicates a marginal point of appropriate carefulness in the sense that, even though it will not be possible to hold a perpetrator who has observed an even higher level of carefulness than the one defined in this manner at fault, the costs incurred on damage prevention means exceed ensuing profits generated within the scope of reductions of expected costs associated with the possible damage; consequently, activities intended to increase safety and minimise potential losses will not be economically

${ }^{25}$ In particular the justification of verdict in the United States v Carroll Towing Co., 159 F.2d 169 (2nd Cir. 1947) case.

${ }^{26}$ For example, it was applied in the case Bammerlin v Navistar Intl. Transport. Corp., 30 F.3d 898, 902 (7th Cir. 1993).

${ }^{27}$ In other words, under Hand's formula, a defined measure of preventative means exists, the application of which is economically rational, dependent upon the probability, or risk of causing a loss (Schäfer and Ott (n 8) 136).

${ }^{28}$ See inter alia comments on this matter and Hand's formula modification in Cooter and Ulen (n 5) 425. 
justified. ${ }^{29}$ Furthermore, it is considered that Hand's formula is only effective when the perpetrator's behaviour leads to a total elimination of the possibility of causing damage, excluding cases in which only a reduction occurs rather than complete elimination. Therefore, for situations in which the applied precautions only reduce to a certain extent the risk of causing damage, it is proposed to amend the aforementioned formula by taking into account two additional factors; namely, the probability of damage occurring when steps are taken which aim to prevent it (hereinafter designated $P_{2}$ ) as well as the expected value of loss in a situation where the potential damage perpetrator undertakes precautions (hereinafter $L$ ). Under such a formula, non-compliance with the required appropriate carefulness, and therefore fault for causing damage will occur if $\mathrm{P}_{2} \mathrm{~L}+\mathrm{B}<\mathrm{P}_{1} \mathrm{~L}$, meaning that the level of damage that would occur as the result of a tort multiplied by the probability of its occurrence when damage prevention means are not undertaken $\left(\mathrm{P}_{1} \mathrm{~L}\right)$ would exceed the sum of costs of preventative means $(\mathrm{B})$ and the level of damage multiplied by its probability in a situation when the perpetrator undertook preventative measures $\left(\mathrm{P}_{2} \mathrm{~L}\right){ }^{30}$

Interestingly, despite the fact that Hand's formula is designed to perform an assessment of whether the perpetrator observed appropriate standards of carefulness and therefore whether he is free from liability or not based on the principle of fault, thereby resulting in it being justified to attribute faulty behaviour to him, an attempt surfaced in literature to use this formula in relation to strict liability (liability based on the principle of risk), although not, of course, to assess whether the perpetrator observed appropriate carefulness within the scope of his activity, since that is legally irrelevant for assigning responsibility for damage under the principle of strict liability. Here Hand's formula was used as a tool for determining the hypothetical conduct of a potential tortfeasor. Namely, it was indicated that if the level of costs to be borne from the application of means to prevent damage to others is lower than the product of the probability of causing damage when no precautions are taken and the value of these losses, then the tortfeasor, faced with the perspective of strict liability, will be inclined to prevent accidents in order to reduce the costs he would incur, and thus will act just as he would when his liability is based on the fault principle. The tort perpetrator whose liability will be based on the principle of risk will act in the same way as under the fault principle, that is to say he will not observe the required carefulness if the aforementioned proportions are reversed; in other words, when the cost of applying preventative measures exceeds the product of the level of probability of the occurrence of damage and its possible cost. From a comparison of these costs it will follow that undertaking preventative measures is simply not profitable. ${ }^{31}$

\section{Frame of reference - standard behaviour of a reasonable person}

Based on objective factors and strictly mathematical calculations in Hand's formula, the question arises of whether, and if so to what extent,

\footnotetext{
${ }^{29}$ RA Posner, Economic Analysis of Law (5th ed, Aspen Publishers 1998) 180-181.

30 J Stelmach, B Brożek, W Załuski, Dziesięć wykładów o ekonomii prawa (Wolters Kluwer 2007) 129.

${ }^{31}$ Posner (n 29)193.
} 
subjective elements should be taken into account; that is, if in determining the model level of appropriate carefulness the individual characteristics of a given person should be taken into account, his capacity to undertake precautions, his wealth, his psychological and physical state, family situation, abilities and education. In the literature it is highlighted that it would be advisable under the various conditions in which individuals operate to take into consideration their individual abilities and financial capacity in respect of undertaking damage prevention means. ${ }^{32}$ In case law practice a standard model is usually adopted for appropriate carefulness, referring to a reasonably acting person who would find himself in such a situation as the party to a given proceedings. It has been observed that courts are willing to take into consideration individual characteristics of the damage perpetrator or the situation in which he finds himself only if the cost of establishing them remains low. Assuming a particular characteristic is easy to establish, usually at first glance, such as when the tort perpetrator is a disabled individual, such an operation would thus be conducted. ${ }^{33}$

\section{E. Other factors of significance for the choice of an optimal principle of liability}

It is obvious that every model of economic analysis of individual legal institutions is based on certain idealistic assumptions, adopted a priori and thus restricting the background of the deliberations. ${ }^{34}$ This is necessary insofar as in practice it is not possible to take into consideration all of the factors affecting human decisions. However, oversimplification of discourse should be avoided, as accounting for too few relevant elements may lead to a false picture of how the actions of parties in respect of tortious liability based on particular principles may be shaped.

In order to simplify analysis and to obtain greater transparency it is generally assumed that people make decisions which are rational for their own good; that there are no legal regulations which lead to a reduction in external costs; that all tortfeasors are solvent at the time when compensation is to be paid, as a result of which full compensation for the damage caused by them is guaranteed; and most importantly it is assumed that administrative costs are equal to zero, and the functioning of insurance systems and the influence of its availability on the behaviour of individuals is not taken into account. This does not belittle the fact that in real life such factors undoubtedly do have what is frequently a very significant influence on decisions concerning conduct made by an individual when the law stipulates tortious liability based on a particular principle as well as in the absence of such liability.

With reference to the assumption on the rationality of actions undertaken by individuals it should be indicated that, along the lines of the

\footnotetext{
32 Miceli (n 15) 26.

${ }^{33}$ Posner (n 29) 183-184.

${ }^{34}$ This is noticed by the authors who are themselves engaged in economic law analysis, who indicate that certain assumptions they adopt are not realistic, but analytically useful (Cooter and Ulen (n 5) 406-410).
} 
assumptions of the economic law school of thought, individuals taking decisions about whether to undertake various activities weigh the associated risks and rewards, and then choose the one which proves the most useful as determined in the course of that reasoning. However, it seems that this is a false assumption to a certain extent, as it is based on the non-realistic belief in people's perfect knowledge about all the costs and risk associated with particular actions; in reality it is imperfect, and it would seem to be appropriate to take this incomplete availability of data into account when conducting analyses. In this context one should consider people's tendency to underestimate the importance of most events by associating a low probability of the occurrence of damage with them, along with those which occur rarely and are not often remembered. One should also consider the tendency to overestimate the danger which may ensue from some other types of activities which carry a small risk of causing injury but are more frequently and dramatically depicted as a source of danger (e.g. in the media). ${ }^{35}$ Therefore, in respect of activities in relation to which their danger is underestimated, people will behave with insufficient carefulness, whereas when overestimating risk they will tend to take excessive precautions; in neither situation will an economically effective outcome be achieved.

When considering the realities of everyday life, it seems overlyidealistic to assume the solvency of damage perpetrators and the ensuing full compensation for the damage which the aggrieved entities suffer, as it is quite often the case that the limited financial capabilities of the perpetrators of damage constitute an insurmountable barrier beyond which they are simply unable to pay compensation. ${ }^{36}$ This threshold is usually quite low when it comes to individuals or enterprises run on a small scale, whereas it may be higher with reference to larger corporations. However, even in the case of the latter, it may not be assumed that there is a one-hundred-percent guarantee of receiving full compensation from them, especially if businessmen sometimes intentionally act to avoid the payment of compensation (eg by conducting activities which may constitute a potential source of damage outside the framework of the core enterprises, for example within the scope of legally separate subsidiaries, by which the liability will be limited to the assets of such a company, which by design will be insignificant ${ }^{37}$ ). The undertaking of such activities by entrepreneurs is especially prevalent when their liability in tort is based on the more rigorous risk principle, where just the fact itself of causing damage results in liability, while less so against the backdrop of the fault principle in the form of negligence, under which the entrepreneur has at his disposal a simpler

35 D Kahneman, A Tversky, Judgement under uncertainty: biases and heuristics (Cambridge University Press 1981); TS Ulen, 'Rational Choice and the Economic Analysis of Law - Law and Social Inquiry' in R Koroblein and TS Ulen, 'Law and Behavioral Science: Removing the Rationality Assumption from Law and Economics' (2000) 88 CLR 1051; Schäfer and Ott (n 8) 229.

${ }^{36}$ Additionally, the possibility to moderate the amount of compensation by the court may be indicated (see art 440 of the Polish Civil Code) by which it may also not lead to full compensation.

${ }^{37}$ AH Ringleb, SN Wiggins, 'Liability and Large-Scale Long-Term Hazards' (1990) 98 JPE 574. 
way of avoiding liability by observing appropriate carefulness in his activities. $^{38}$

Aside from the aforementioned considerations, an assumption of complete compensation for damage suffered by aggrieved entities transpires to be an illusion, especially in the non-material context of personal injuries, as some harm in the form of death or serious injury as well as negative psychological experiences, pain or emotional suffering simply cannot be expressed by a given monetary amount that would constitute compensation (money will never compensate the loss of a loved one). Furthermore, it should be noted that in the event of a danger to life and health the potentially aggrieved individuals will tend to undertake appropriate precautions on their part, even in a situation where a certain principle is established by law on which the tort perpetrator's liability is such that the tortfeasor's obligation to pay compensation will not be diminished in any way, even if the aggrieved had not observed appropriate carefulness in their own behaviour. Here the fundamental motivation of potential victims for observing carefulness will stem not from visions of receiving or not receiving compensation, but from the wish to avoid death or serious injuries, as these definitely represent a greater value. It is possible that the perspective of redress in the event of personal injury may lead to a very slight reduction in their carefulness, but this is doubtful. The reduction in the level of precautions undertaken by potentially aggrieved entities seems at its most possible with reference to the threat of damage restricted solely to assets. ${ }^{39}$ Furthermore, there is no doubt that an extremely important factor determining the behaviour of individuals in practice, including the decision to pursue a compensation claim from the perpetrator of a given injury on the grounds of his liability in tort based on a defined principle, is the issue of the necessity to bear the costs associated with bringing a suit against the tortfeasor, especially in the context of the overall profitability of actioning such claims. These costs are usually identified as the costs of court proceedings, although the position is also emerging to understand this concept in a broader sense by including the expenses associated with entering into settlements and even the costs associated with the time, effort and emotions sacrificed. ${ }^{40}$ A significant influence on the behaviour that has developed among legal entities due to the governance of individual liability in tort principles has also undoubtedly been the availability of insurance policies pertaining to the civil liability of potential perpetrators, as well as those for the potentially aggrieved, against personal injury or damage suffered as a result of the actions of other persons. This mostly stems from the fact that in the event such an insurance agreement is entered into, the entire system of incentives which are to affect the behaviour of potential tort perpetrators and entities incurring a damage as the result, which was shaped as a result of legal solutions establishing liability in tort based on a given

\footnotetext{
${ }^{38}$ Cooter and Ulen (n 17) 322.

${ }^{39}$ Similarly, although less categorically: RA Posner (n 2) 185-186.

${ }^{40}$ Shavell (n 13) 417. See also Miceli (n 15) 44.
} 
principle, becomes distorted. ${ }^{41}$ Another important factor affecting the possibility of causing damage and its scope is whether a given entity will undertake a given activity, and for how long. ${ }^{42}$ For a detailed discussion of the significance of all the factors given herein, i.e. administrative costs, insurance policies, the level of an entity's activity etc., one is referred to the literature on the subject due to the limited scope of this work. ${ }^{43}$ However, it remains beyond doubt that they are among the most significant to be taken into account when conducting economic analysis of the principles of liability in tort.

\section{CONCLUSION}

In light of the observations made in this article one should conclude that economic analysis of law is not a perfect method, but one which undoubtedly limits the scope of consideration and treats the issue of the functioning of law solely through the prism of economic principles, passing over other important factors. There are also objections raised in the literature that this is not a scientific method but only a normative variety of the economically-oriented policy of law, mostly due to the fact that because of the significant number of assumptions which are impossible to verify, it is difficult to acknowledge its descriptive character. ${ }^{44}$ The proponents of this method themselves are aware of its limitations, such as the conventionality of some assumptions or the fact that it is practically impossible to express them in a manner which does not raise doubts. The assumption that man is homo economicus, making the most efficient choices for himself raises objections, because such an attitude not only fails to take into account other important factors influencing the human decision processes, such as emotions or psyche (which often lead to irrational behaviour from an economic point of view), but also elements operating within the sphere of economics, such as the wealth effect or the manner of presenting available options for choice and the freedom of such choice.

Nevertheless, it should be acknowledged that pointing out the imperfections and gaps in the applied method is in itself valuable, as this leads to its continual improvement. The conclusions obtained in the course of reasoning will obviously be more correct when a greater volume of situational factors is taken into account and the data better reflect reality. However, for methodological reasons it is impossible to take into consideration all of the aspects in all possible situations which are taken into account by individuals making decisions as to undertaking or refraining from actions which may bear a risk of causing damage to someone else. Omitting the practical impossibility of doing so, such a detailed analysis would not yield results on a level sufficiently general for formulating principles of broad and universal significance with aspirations to be

\footnotetext{
${ }^{41}$ Schäfer and Ott (n 8) 121; SR Gross, KD Syverud, 'Don't try: Civil Jury Verdicts in a System Geared to Settlement' (1996) 44 UCLA LR 19-22.

${ }^{42}$ S. Shavell, 'Strict Liability versus Negligence' (1980) 9 JLS 1-25; Shavell (n 13) 403; T.

J. Miceli (n 15) 28; Schäfer and Ott (n 8) 167-169.

${ }^{43}$ See footnotes $40-42$.

${ }^{44}$ J Stelmach (n 1) 16-17.
} 
representative for a given society. Thus an attempt to establish economic rules adequate for everyone requires a certain, sometimes significant level of generalisation.

In light of the above, the application of the tools of economic analysis to law, both for the assessment of existing legal regulations pertaining to liability in tort, as well as for the needs of formulating de lege ferenda postulates, seems helpful; nevertheless, due to the aforementioned limitations, it should be treated as a supplement, and never the primary nor sole method of assessing legal regulations. 